\title{
Social Work and the environment. Understanding people and place.
}

\author{
Michael Kim Zapf. Toronto: Canadian Scholars' Press, \\ 2009, pp. 229
}

Felipe Saravia*

Para Trabajo Social es necesario remirar de forma constante las herramientas conceptuales con que trabaja, en la búsqueda de hacerse de perspectivas que logren dar cuenta de forma profunda y crítica de los fenómenos que aborda.

Desde hace tiempo, diversos autores vienen cuestionando la centralidad del concepto "comunidad" en la aproximación al trabajo social con colectivos. En este contexto, se ha echado mano a conceptos tales como "territorio" (Elpidio, 2016), "espacio" (Jeyasingham, 2014), "lugar" (Akesson, Burns y Hordyk, 2017), o "urbano" (Williams, 2016), entre otros. Sin embargo, la penetración de estos debates en el contexto latinoamericano o nacional parece ser incipiente y poco vinculada con debates internacionales en esta materia. Como plantea Teresa Matus, "en muchos centros académicos, se asume una corriente contemporánea como si fuese la única existente y a los otros enfoques se los trata como incipientes o erróneos o simplemente se los desconoce. A este proceso le ayuda una especie de insularidad lingüística continental, donde el número de referencias bibliográficas de intercambio entre corrientes es bastante pobre" (2018, p. 12).

Por esta razón, en la búsqueda de una problematización de lo que he denominado "espacialidades de la intervención social" (Saravia, 2019), he asumido la tarea de rastrear la producción intelectual que vincula trabajo social con distintos conceptos que se asocian a expresiones espaciales.

\footnotetext{
* Chileno. Trabajador Social, magíster en desarrollo humano a escala local y regional, y doctor en ciencias sociales en estudios territoriales. Universidad del Bío-Bío. E-mail: fsaravia@ubiobio.cl
} 
La reseña aquí presentada se inserta en ese esfuerzo. Una posible traducción no literal del título del libro reseñado podría ser "Trabajo Social y ambiente: entendiendo la relación entre personas y los lugares". Su autor, Michael Kim Zapf, es trabajador social canadiense, académico - ya jubilado - de la Facultad de Trabajo Social de la Universidad de Calgary, con experiencia en el trabajo con comunidades indígenas en dicho país, específicamente en territorio Yukón. Precisamente dicha experiencia fue, según lo indica al comienzo de su relato, lo que gatilló en él la inquietud por el desarrollo de una perspectiva que comprendiera de forma amplia y profunda el vínculo entre las personas y el ambiente físico en los que estas desarrollan su vida, especialmente en lo relacionado con el trabajo social.

Comienza su libro destacando la creciente centralidad que los asuntos ambientales tienen para la sociedad en general, debido a diversos fenómenos, tales como el cambio climático o conflictos socioambientales en diversos países. Sin embargo, se pregunta: "si los asuntos ambientales han llegado a la cima de la lista de prioridades para la acción pública, ¿dónde está la profesión del trabajo social en relación con esas nuevas y urgentes preocupaciones?" (Zapf, 2009, p. 17).

Si bien en el contexto anglosajón existe cierta tradición en el trabajo social, vinculada de forma explícita con lo urbano - ver, a modo de ejemplo, Urban social work, de Kolko y Ashenberg (2002)—, Zapf indica que esta no toma suficientemente en consideración la relación entre las personas y su entorno físico. Plantea que, en la perspectiva tradicional en nuestra profesión, el ambiente físico es visto como algo estático, un mero contexto para la actividad humana, algo así como un escenario para las escenas que desplegamos a lo largo de nuestra vida.

Frente a ello, Zapf plantea que "es tiempo de que el Trabajo Social vaya más allá de la convencional metáfora de persona en ambiente hacia un nuevo paradigma, una nueva comprensión sobre la relación entre las personas y el ambiente físico" (2009, p. 18).

En este sentido, lo que el autor busca a lo largo del libro es superar la metáfora de persona en ambiente (person-in-environent) que, según su argumentación, ha llegado a establecerse como la corriente principal del trabajo social, y que se remontaría a los orígenes de la profesión. En efecto, al referirse al trabajo de Mary Richmond plantea que, 
aunque hace una distinción entre las dimensiones físicas y sociales del ambiente como influencias en el comportamiento humano, y reconoce el ambiente físico como una consideración contextual relevante para el trabajo social, percibe su importancia solo en términos de sus aspectos sociales. Esta negación de la relevancia que el ambiente físico tiene en sí mismo en el quehacer profesional y disciplinar, es analizada también a lo largo de una exhaustiva revisión de literatura académica en las décadas de 1980, 1990 e incluso en la década del 2000. Durante todo este tiempo, la sociedad para Trabajo Social ha sido el asunto principal de análisis y atención, mientras que el mundo natural es visto como accesorio, o mero contexto.

Ahora bien, a pesar de este escenario general, Zapf identifica un conjunto de propuestas que en alguna medida avanzan en la incorporación del ambiente en el quehacer de Trabajo Social. Menciona aportes desde perspectivas ecológicas, o algunos trabajos que hacen referencia a conceptos tales como "territorialidad", "espacio personal", entre otros. Adicionalmente, se refiere a trabajos que vinculan Trabajo Social con el activismo medioambiental, y el trabajo de autores que defienden la necesidad de una perspectiva eco-social.

Entre los capítulos cuatro y siete el autor ahonda en distintas expresiones del ambiente en las realidades con las que trabaja Trabajo Social. El capítulo cuatro se refiere al trabajo social rural o remoto que, especialmente en la década de 1970, llegó a constituir un subcampo relativamente reconocido de producción intelectual en el trabajo social norteamericano. Al revisar esta materia, Zapf refuerza una tesis central del libro: los lugares no solo condicionan los fenómenos sociales que Trabajo Social atiende, sino al trabajo social mismo: "trabajo social no es solo creado en cualquier lugar y luego hecho o impuesto en áreas rurales o remotas. Es creado o hecho en cada lugar" (Zapf, 2009, p. 90).

El capítulo cinco aborda el ambiente como algo sagrado, la espiritualidad, la ecología profunda y perspectivas indígenas respecto del ambiente. En términos generales, lo que Zapf observa es que cuando la literatura académica en Trabajo Social aborda lo ambiental, la dimensión espiritual desaparece de la discusión. Sin embargo, desde la ecología profunda y las perspectivas indígenas no parece coherente la disociación entre ambiente físico y espiritualidad. El autor plantea la necesidad de avanzar hacia perspectivas holísticas del ambiente que 
incluyan también esta dimensión, y la interrelación profunda entre las personas y los lugares.

En el capítulo seis el libro aborda cómo el Trabajo Social internacional aborda asuntos relacionados con el medio ambiente, el desarrollo y la sustentabilidad. En el capítulo siete se abordan perspectivas provenientes desde otras disciplinas diversas, tales como la pintura (con referencia al concepto de "paisaje"), la cinematografía (como una forma de contar los lugares), la música (con referencia al concepto de "paisaje sonoro" como expresión de localidades), la viticultura (con referencia al concepto de "terroir" y el valor de los lugares), la sociología (refiriéndose específicamente al concepto Bourdieano de "habitus", como un sentido de lugar incorporado), la psicología (con referencia a los conceptos de "ambiente", "lugar" y sus relaciones con el comportamiento humano), el diseño ambiental, la geografía, y la educación. En suma, si bien la revisión del abordaje de lo ambiental en cada una de estas disciplinas no es exhaustiva, permite al autor reconocer que se está frente a un fenómeno que necesariamente implica abordajes multidisciplinarios.

A partir de lo anterior, el penúltimo capítulo fundamenta la necesidad de contar con nuevas metáforas que expliquen cómo trabajo social debe abordar lo ambiental. En este sentido, se opera desde el supuesto de que el lenguaje que usamos para explicar tanto los fenómenos con que trabajamos, como nuestro propio quehacer como profesión y disciplina, condiciona lo que somos capaces de observar y la forma en que operamos en concreto.

Finalmente, el autor desarrolla su propia metáfora, que podría reemplazar la tradicional perspectiva de persona en ambiente. Plantea entender las personas como lugares (people as place). Ello se fundamenta especialmente en "las enseñanzas del trabajo social indígena que han introducido las nociones de la vida buena, el gran misterio que mora en todo lo existente, la naturaleza como un lugar de creación, un regalo de la tierra, y la relación entre todas las cosas" (Zapf, 2009, p. 184).

El cambio de concepto de ambiente a lugar es fundamentado en el entendido de que el concepto "lugar" combina la locación, el ambiente físico y el carácter, el sentido y la significancia emocional para 
las personas. Adicionalmente, se entiende a las personas como lugares para enfatizar la inseparabilidad de ambas dimensiones. No es posible pensar las personas sin el ambiente natural, y viceversa. En este mismo sentido, la metáfora propuesta hace referencia también a la idea de la vida buena como horizonte ético-político, lo que implicaría integrar a esta perspectiva la justicia social en interrelación con la justicia ambiental, los derechos humanos con los derechos medioambientales, y las responsabilidades humanas con las responsabilidades medioambientales.

Ahora bien, los lectores que estén buscando un manual completo sobre cómo hacer trabajo social ecológico podrían sentirse defraudados al finalizar la lectura de este libro, pero el autor plantea que, como disciplina, no estamos aún en ese punto, ya que hacer cambiar la corriente principal del trabajo social es una tarea enorme, que debe comenzar con una fundamentación adecuada de nuevas perspectivas, con un horizonte de propósito claro, a lo que el libro reseñado hace un aporte interesante: "yo he sugerido una dirección para las próximas etapas de la construcción de modelos basados en el entendimiento de las personas como lugares. Recae en la próxima generación de trabajadores sociales y académicos completar este trabajo" (Zapf, 2009, p. 194).

En suma, estamos ante un trabajo que resulta interesante revisar, no solo porque realiza un estudio bastante exhaustivo de la producción intelectual que el Trabajo Social anglosajón ha realizado en torno a asuntos ambientales, sino que también propone una perspectiva propia que releva los conocimientos indígenas y entiende de manera más profunda la relación entre las personas y los lugares.

Sin embargo, la revisión realizada por el autor se remite a la disponible en inglés, por lo que no logra desarrollar comparaciones que vayan más allá del contexto anglosajón, si bien hace mención de los pueblos originarios de Norteamérica. Es necesario avanzar hacia análisis realmente globales, que contemplen lo que ocurre en el Trabajo Social no solo en Norteamérica, Europa y Oceanía, sino también en Asia, África, y América Latina. Trabajos de esta naturaleza implican esfuerzos intelectuales importantes, que requerirán la articulación de organismos diversos en distintos países. Por último, como planteo en otros escritos (Saravia, 2020), es necesario no solo hacer un trabajo en 
nivel de abstracción teórica general, sino revisar las implicancias de teorizaciones específicas sobre fenómenos concretos, y el desarrollo de metodologías de intervención en vinculación con dichas teorizaciones, en articulaciones entre academia, organizaciones dedicadas a la intervención social, y movimientos sociales. Las escuelas de Trabajo Social latinoamericanas tenemos mucho trabajo por delante.

\section{Bibliografía}

Akesson, B., Burns, V. \& Hordyk, S. (2017). The Place of Place in Social Work: Rethinking the Person-in-Environment Model in Social Work Education and Practice, Journal of Social Work Education, 53(3), 372-383. DOI: 10.1080/10437797.2016.1272512.

Jeyasingham, D. (2014). The production of space in children's social work: Insights from Henri Lefebvre'sspatial dialectics. British Journal of Social Work, 44(7), 1879-1894. DOI: 10.1093/ bjsw/bct053.

Matus, T. (2018). Punto de Fuga. Tomo I. Imágenes dialécticas de la crítica en el Trabajo Social contemporáneo. Buenos Aires: Espacio editorial.

Elpidio, M. H. (2016). Território, política social e serviço social. Campinas: Papel Social.

Saravia, F. (2020). Epílogo. Sobre cómo seguir avanzando, en F. Saravia, M. A. Urquieta y M. B. Ortega, Espacialidades en la intervención social: Debates para el Trabajo Social latinoamericano. Santiago de Chile: RIL editores.

Saravia, F. (2019). Hacia la constitución de un campo sobre las espacialidades de la intervención social. Revista Transformación Socio-Espacial, 1(1), 5-7. DOI: 10.22320/24525413.2019.01. 01.00 .

Williams, Ch. (2016). Social work and the city. Urban themes in $21^{\text {st }}$ century social work. Londres: Palgrave Macmillan.

Zapf, M. (2009). Social Work and the environment. Understanding people and place. Toronto: Canadian Scholars' Press. 